\title{
Studies on production of low calorie lassi
}

\author{
Brahamani. D, Kotilinga Reddy.Y, Vijaygeetha V and KN Rao
}

Received: 06 March 2020 / Accepted: 16 July 2020 / Published online: 27 October 2020

(C) Indian Dairy Association (India) 2020

\begin{abstract}
Lassi containing the artificial sweeteners was compared with control sample containing sugar for quality parameters. Aspartame was used at 80,90 and $100 \mathrm{ppm}$, and sucralose at 20,25 and $30 \mathrm{ppm}$ levels for total replacement of sugar during production of low calorie lassi. Based on the physico-chemical and sensory quality parameters, lassi added with $90 \mathrm{ppm}$ aspartame and $25 \mathrm{ppm}$ sucralose were found to be acceptable compared to control lassi. To achieve the mouthfeel of the finished product as that of control lassi, a bulking agent i.e. sorbtiol was added at three different levels i.e. 7, 7.5 and 8.0\% respectively to the selected levels of sweetener. It was found that 7.5 per cent sorbitol level was more suitable than the lassi prepared with 7.0 and 8.0 levels of sorbitorl with respect to physico-chemcial and sensory quality. Satisfactory quality low calorie lassi was prepared by using artificial sweeteners viz . sucralose and asparatame along with sorbitol.
\end{abstract}

Keywords: Aspartame, Lassi, Low calorie lassi, Sucralose, Sorbitol,

Lassi is considered as digestive, nutritive and useful in gastrointestinal ailments. The health benefits of lassi are the result of biologically active components that are present in native milk and also due to suitably modulated activities produced through the action of lactic acid bacteria, and used for the treatment of diarrhea, dysentery, chronic specific and non specific colitis, piles

Department of Dairy Technology, College of Dairy Technology, Sri Venkateswara Veterinary University, Tirupati-517502. A.P. India

Kotilinga Reddy.Y $(\bowtie)$

Department of Dairy Technology, College of Dairy Technology, Sri Venkateswara Veterinary University, Tirupati-517502. A.P. India

Email:ykotilingareddy@yahoo.com and jaundice (Padghan et al. 2015). Diabetes is a heterogeneous primary disorder of carbohydrate metabolism and it affected around 171 million people worldwide in 2000 and this number may increase to at least 366 million by 2030 . According to India's current national survey, more than $20 \%$ of the Indians are overweight or obese. Every fifth diabetic in the world is an Indian and India is the diabetes capital with 6.22 crore diabetic patients, which will reach to 8 crore in 2030 (Vairagade et al. 2016). Dairy products are occupying the major part in human diet every day, however they become a setback for health conscious, diabetic and obese people due to the presence of sugar and fat in sufficient quantity. Milk products traditionally used contain 8$10 \%$ sugar which provides $32.8-41 \mathrm{Kcal} / 100 \mathrm{gm}$. The sugar in milk and milk products

contribute to overweight and acts as promoting factor for diabetes. To overcome the disorders, generally sugar is replaced with artificial sweeteners to reduce the calorific value of the products. Several texturizers such as pectin and gums have been proposed for use in low calorie beverages to compensate the texture loss and mouth feel (Saha and Bhattacharya, 2010; Berry, 2013). Artificial Sweeteners are also known as intense sweeteners because they are many times sweeter than the natural sugars like cane sugar. Artificial sweeteners are synthetic sugar substitutes but may be derived from naturally occurring substances, including herbs or sugar itself (Sushim Chaudry, 2015). Recently Indian government has permitted the use of artificial sweeteners in traditional dairy products. Based on the requirements of the consumers in the dairy industry the present investigation was undertaken to develop a low calorie lassi beverage using low calorie artificial sweeteners along with bulking agent for the diabetic and calorie conscious people.

For preparation of low calorie lassi, food grade sorbitol syrup (70\% TSS) was procured from Vintop Products Pvt. Ltd., Mysore Road, Bangalore, intense sweetener aspartame (sugar free) was procured from Changzho Nioutang Chemical Pant Co. Ltd., Niutang Town, China whereas sucralose was procured from Shandong Kanbosweet Inc., Shandong, China. Lassi (control) was prepared as per standard procedure of Aneja et al. 2002 by using milk standardized to $3.5 \%$ fat and $8.5 \%$ SNF. Initially the milk is preheated to $60-65^{\circ} \mathrm{C}$ and homogenized @2000 psi in I 
stage and $500 \mathrm{psi}$ in II stage then apply heat treatment $@ 90^{\circ} \mathrm{C}$ for 10 min and cooled to $30^{\circ} \mathrm{C}$. Then add dahi culture@2 per cent level and incubate about $37^{\circ} \mathrm{C}$ around 12 hours. Then break the curd and blend for 50 per cent pasteurized water and mix thoroughly with agitator. Then add $12 \%$ sugar as sweetening agent and 0.2 per cent vanilla used and packed in PET/PP cups and stored at $4 \pm 1^{\circ} \mathrm{C}$.

Preparation of lassi with low calorie sweeteners and bulking agent: The procedure of lassi preparation was same as that of control sample as explained above; however, sugar was replaced with sucralose and aspartame. Aspartame (80ppm, 90ppm and 100ppm) and sucralose $(20 \mathrm{ppm}, 25 \mathrm{ppm}$, and $30 \mathrm{ppm})$ were used to completely replace sugar. Further to improve the mouth-feel and viscosity of the product, sorbitol was used as bulking agent at the rate of $7.0 \%, 7.5 \%$, and $8.0 \%$ along with the two artificial sweeteners.

The lassi was evaluated for physico-chemical and sensory characteristics. Fat, SNF content in raw milk and lassi were determined by Gerber method and Rose-Gottlieb method as described in IS: $1224-1958$ and A.O.A.C, 2000 respectively. Viscosity of lassi (cp at $25^{\circ} \mathrm{C}$ ) was determined at $20^{\circ} \mathrm{C}$ using Brookfield viscometer. $\mathrm{pH}$ of lassi was determined by a digital pH meter ElicoPvt Ltd., Hyderabad .Titratable acidity of lassi was determined as per the method given in (IS: 1479, Part-1,1960). The acceptability of lassi prepared by substituting sugar with low calorie sweeteners along with bulking agent was evaluated by conducting sensory evaluation by a panel of trained judges using 9-point hedonic scale. The results were analysed by statistical R core team.
On perusal of results presented in Table 1 it was observed that there was no significant difference between sweeteners and between sweetener levels and control in $\mathrm{pH}$ and acidity. It was observed that the initial $\mathrm{pH}$ and acidity of the milk did not get influenced by the addition of two low-calorie sweeteners. Artificial sweeteners added to yoghurt did not cause greater rise in acidity or reduction in $\mathrm{pH}$ during storage (Sabahat Yaqub et al. 2018). The results are also corroborated by the findings of El. Tahra et al. (2015) who reported that incorporation of honey at $2 \%, 4 \%$ and $6 \% \mathrm{w} / \mathrm{v}$ in yoghurt did not significantly influence the $\mathrm{pH}$ and lactic acid levels of the product. The viscosity was greater in control when compared to the artificial sweeteners added lassi. Statistically it was found that there was no significant difference between sweeteners however a significant difference $(\mathrm{p}<0.01)$ was found between control and sweeteners levels. It is evident that the lassi made with two low calorie sweeteners at different levels had significantly lower mean viscosity than the control wherein the sugar directly contributed to the viscosity. The present findings are in agreement with the results observed during the preparation of low calorie chocolate flavoured milk made with aspartame stevia and sucrose in different proportions by Aziz et al. (2012) and wherein the viscosity of control lassi was higher when compared with lassi by incorporation of concentrated and lactose hydrolyzed whey.

The mean flavour score of control lassi containing 12\% sugar was 8.5. Acceptable sweetness in 25 ppm sucralose added lassi was observed by the panellists. This was equal to the perceptiveness of the lassi made with sugar without any after taste compared to the other two levels viz., 20 and 30 ppm added lassi. It was observed from the mean flavour scores of sucralose

Table 1 Influence of sweeteners' level on physico - chemical and sensory quality (1-9 score) of lassi without bulking agent

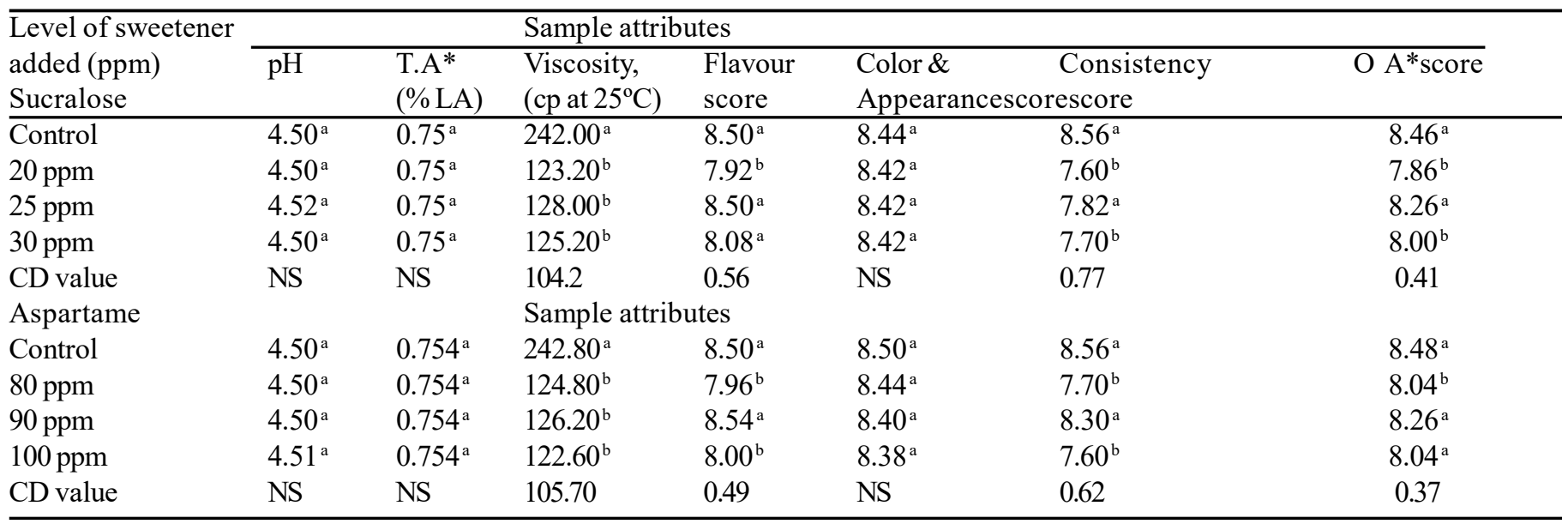

*T.A - Titratable acidity

*OA - overall acceptability

All values are average of five trials

Control - Lassi added with sugar@12\% level on milk basis

NS - Non significant

Similar superscripts in a column indicate non-significant at the corresponding critical difference $(\mathrm{P}<0.05)$ 


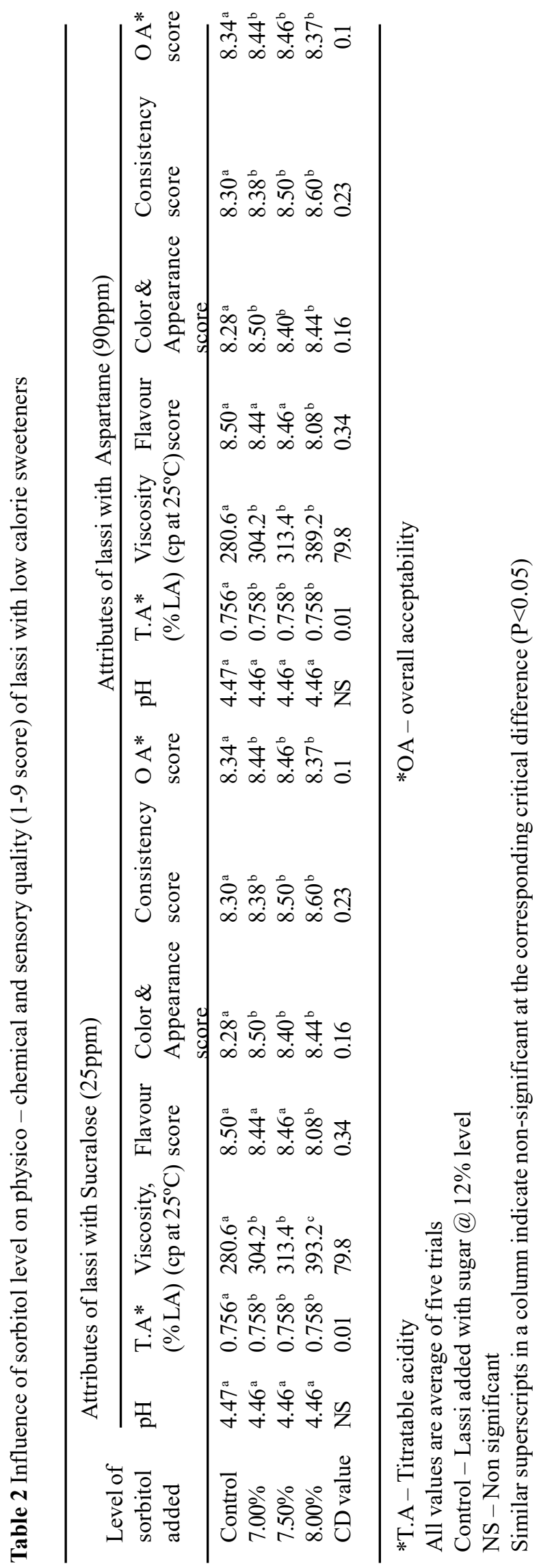

added lassi that there was a significant difference between the sweetener levels and control. These findings are in agreement with the results of low calorie sterilized flavoured milk made with $75 \mathrm{ppm}$ sucralose (Natraj, 2008) wherein a higher level of sucralose was added to the mix to meet sterilization losses. The colour and appearance mean score values were more or less stable between the three levels of sucralose added lassi. However, there was no significant difference between levels when compared to control. Further, it was observed from the mean consistency scores of sucralose added lassi that there was a significant difference between the levels and control, as sugar is contributing ingredient to the consistency. The observations are in conformity with the findings of Arora et al. (2008) who reported insufficient water binding capacity of artificial sweetener which resulted in a product with lower consistency. In addition, there was a significant difference between the levels and control observed with the mean overall acceptability scores of sucralose added lassi.

The average mean flavour score for aspartame added lassi without bulking agent for the level of $90 \mathrm{ppm}$ aspartame was found to be best compared to the level of 80 and $100 \mathrm{ppm}$. It was observed from the mean flavour scores of aspartame added lassi that there was a significant difference between the levels and control. However, 80 and $100 \mathrm{ppm}$ aspartame added lassi were found to be having low and higher degree of perceptible sweetness respectively and was not comparable to that of control. The results are comparable with the findings of Arora et al. (2008). The colour and appearance mean score values of the three levels of aspartame as well sucralose added lassi had no significant difference between levels when compared to control. Evidently, Arora et al. (2008) reported that the colour and appearance score were significantly lower $(\mathrm{p}<0.05)$ for artificially sweetened kalakand as compared to control. It was observed from the mean consistency scores of aspartame added lassi that there was a significant difference between the levels and control. Evidently, addition of sugar in control contributed a higher mean consistency scores than the aspartame added lassi without sugar. The mean overall acceptability scores of aspartame added lassi showed that there was a significant difference between the levels and control. The results are comparable with the study done by Rathod et al. (2013) indicating that with increase in the level of aspartame, there is a significant difference between the levels and control and Arora et al. (2008) studied that sucrose was successfully replaced with the sweetener aspartame for the preparation of lassi and flavoured milk. Aspartame at a level of $0.07 \%$ in flavoured milk and $0.08 \%$ in lassi on milk basis scored highest in terms of sweetness perception and resembled control prepared with sucrose.

Sorbitol is a polyhydric alcohol which contributes to all aspects of sweetener functionality including sweetness, bulking and freezing point depression. As it has the same calorie value of sucrose it cannot be used for calorie reduction. However, in diabetic dairy products it replaces sugar from the aspect of 
providing some of the bulk and mouth feel and also some sweetness. The average flavour score for $7.5 \%$ incorporation of sorbitol was 8.46 , which was higher than 7 and $8 \%$ level of addition (Table 2). Some amount of sweetness is contributed to the lassi through sorbitol, the optimum perceptible sweetness was appreciated by the judges in $7.5 \%$ level incorporation which is slightly lower than that of control. Statistically, it is supported by showing a significant difference between the $8 \%$ sorbtiol added lassi and control lassi. The mean colour and appearance, consistency and overall acceptability scores were significantly different between the sorbitol levels and control. It is evident from the study that sorbitol contributed good body and texture and mouth feel to product compared to the sugar containing control lassi. Further, an acceptable and appreciable colour and appearance of the product was observed in lassi made with sorbitol than sugar made lassi. Jayaraj Rao and Pagote, (2018) suggested use of 40 brix sorbitol solution containing $14.3 \mathrm{mg} / \mathrm{L}$ Asparatame for low calorie rasogolla. Further Narendra Raju and Dharampal, (2011) confirmed that use of asparatame and acesulfame-k at $0.38 \mathrm{~g} / \mathrm{Kg}$ and $0.35 \mathrm{~g} / \mathrm{Kg}$ along with $14 \mathrm{~g} / \mathrm{Kg}$ of maltodextrin gave highly acceptable quality of Mishti dahi. Nataraj (2008) standardized the level of sorbitol content in development of low calorie sterilized flavoured milk and found that addition of 8 per cent sorbitol recorded an optimum sensory scores than 7.5 $\%$ level. Based on the sensory attributes in the above study, $7.5 \%$ sorbitol and $25 \mathrm{ppm}$ sucralose added low calorie lassi were found to be highly desirable when compared to others.

The average flavour score for $7.5 \%$ incorporation of sorbitol was 8.46 which was higher than 7 and $8 \%$ level incorporated products. Some amount of sweetness was contributed to the lassi through sorbitol, the optimum perceptible sweetness was appreciated by the judges in $7.5 \%$ level incorporation which was slightly lower than that of control. Statistically it was supported by showing a non-significant difference between the sorbtiol levels and control. The mean colour and appearance, consistency and overall acceptability scores were significantly different between the sorbitol levels and control. Based on the above study, low calorie lassi made with incorporation of $7.5 \%$ sorbitol with $90 \mathrm{ppm}$ aspartame showed acceptable perceptible sweetness. Finally, based on the above study it was found that the following flow diagram can be evolved for production of low calorie lassi made with two artificial sweeteners along with the bulking agent sorbitol

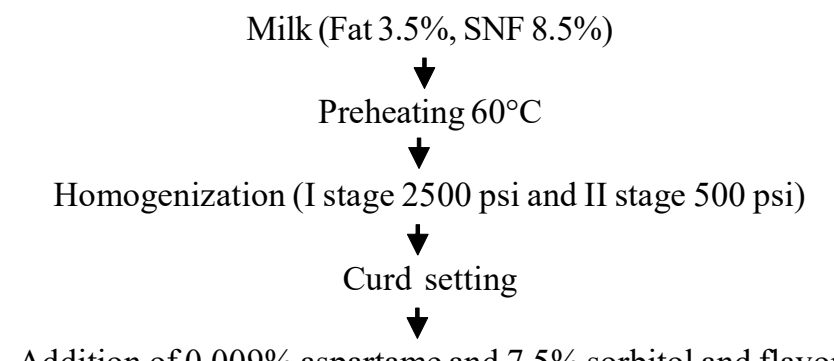

Addition of $0.009 \%$ aspartame and $7.5 \%$ sorbitol and flavor or

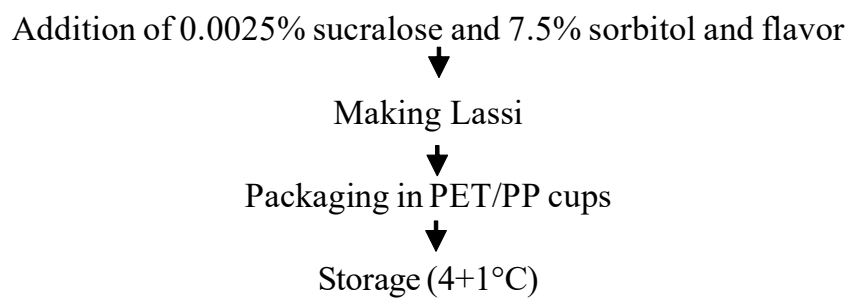

The calorific value of $25 \mathrm{ppm}$ sucralose $+7.5 \%$ sorbitol, $90 \mathrm{ppm}$ Aspartame $+7.5 \%$ sorbitol added low calorie lassi and control lassi made with $12 \%$ sugar (on milk basis) were found to be 66.8 , 66.20 and $86.92 \mathrm{Kcal}$ of energy per $100 \mathrm{~g}$ respectively. Further, it was found that on calculation there is was $23 \%$ and $23.8 \%$ reduction in calorific value of the above two low calorie lassi respectively than compared to control.

\section{Conclusion}

Based on the physico - chemical and sensory evaluation, it was found that lassi made with $7.5 \%$ sorbitol plus $25 \mathrm{ppm}$ sucralose and $7.5 \%$ sorbitol plus $90 \mathrm{ppm}$ asparatame were highly acceptable compared to the control.

\section{References}

AOAC (2000) The Official Methods of Analysis of AOAC International, edited by W Horwitz, $17^{\text {th }}$ edn, Washington D.C. pp 991-29

Aneja RP, Mathur BN, Chandan RC, Banerjee AK (2002) Cultured Fermented Products. In: Traditional Indian Milk Products. Dairy India Publication, New Delhi, India, pp 177-179

Arora S, Sharma V, Gawande H, Wadhwa BK, George V, Sharma GS, Singh AK (2008) Stability of aspartame in lassi and flavoured milk during storage. Indian Dairyman 60: 14-17

Aziz Homayouni Rad, Zohre Delshadian, Seyed Rafi Arefhosseini, Beitollah Alipour, Mohammad Asghari Jafarabadi (2012) Effect of inulin and stevia on some physical properties of chocolate milk. Health Promote Perspects 2: 42-47

Berry D (2013) "Beverage Texture: A Growing Challenge."http:// www. foodbusinessnews.net/articles/news_home/SupplierInnovations $/ 2013 / 01 / \quad$ Beverage_texture_growing c ha 11 . a s p x ? I D = \% 7 B C $0853-23$ B $9-4206-$ A 565 8E84AAB767D\%7D\&cck=1accessedMay 15.

El-Tahra MA, Ammar Magdy M. Ismail, Abd El-Wahab E. Khalil, Mohamed Z. Eid

(2015) Impact of fortification with honey on some properties of bioyoghurt. J Microbiol Biotech Food Sci 4: 503-508

Indian Standards Institution 1958 Methods of test for Dairy Industry, New Delhi.

IS: 1479 (Part-I), (1960). Methods of test for dairy industry: Rapid examination of milk. Indian Standards Institute. ManakBhavan, New Delhi

IS 1224-1958 (1958): Determination of fat by the gerber method, Part 2: Milk products [FAD 19: Dairy Products and Equipment]

Jayaraj Rao K, Pagote C N (2018) Use of artificial sweeteners in indian traditional dairy products. Food Nutr J 3: 1-8

Narender Raju P, Dharam Pal (2011) Effect of bulking agents on the quality of artificially sweetened misti dahi (caramel colored sweetened 
yoghurt) prepared from reduced fat buffalo milk. Food Sci Technol 44: $1835-1843$

Natraj K B (2008) Studies on production of sterilized flavoured milk with low calorie sweeteners. M. Tech (Dairying) thesis submitted to S.V. Veterinary University, Tirupati

Padghan PV, Bimlesh Mann, Rajesh Kumar, Rajan Sharma and Anil Kumar (2015) Studies on biofunctional activity of traditional lassi. Indian J Traditional Knowl 1: $124-131$

Rathod KR, Londhe, Naik (2013) Optimization of levels of artificial sweetener for preparation of sugar free ice- cream. Asian J Dairy Food Res 32: 266-274
Sabahat Yaqub, Hafiz Arbab Sakandar, Nuzhat Huma, Faizan Ahmed Sadiq, Qaiser, Farid Khan,

Muhammad Imran, Abdur Rehman, Rashida Perveen, Ayesha Sameen (2018) Effects of artificial sweeteners on the quality parameters of yogurt during storage. Progress Nutr 20: 57-63

Saha D, Bhattacharya S (2010 Hydrocolloids as thickening and gelling agents in food: a critical review. J Food Sci Technol 47: 587-97

Sushim Chaudhary (2015) Unbiased truth about artificial sweeteners. Int J Clin Biomed Res 2: 38 - 40

Vairagade A S, Patil, Gawande, Dhotre (2016) Preparation of carrot halwa with aspartame and storage. Indian J Dairy Sci 70:79-86 